\title{
Comparative Study of Peripheral Blood Smear, Modified Centrifuged Blood Smear And Dipstick Method In Diagnosis of Malaria With Evaluation of Hematological Parameters
}

\author{
Jawarkar Ashish1, Vyas Arun2 \\ ${ }^{I}$ (Assistant Professor, Parul Institute Of Medical Sciences And Research, Vadodara, India) \\ ${ }_{2}^{2}$ (Associate Professor, Grant Medical College And Sir J.J. Group Of Hospitals, Mumbai, India)
}

\begin{abstract}
Nonspecific clinical presentation of malaria leads to overtreatment in endemic areas and missing the diagnosis in low transmission areas. The Peripheral Blood smear is an established method in malaria diagnosis. However low sensitivity, cumbersome technique and need for specially trained persons for interpretation limits its usefulness. The antigen detection method is highly sensitive and specific method, however mixed cases have to be confirmed on smears and quantification of parasitemia cannot be done, also it involves high cost. This study aims to establish Modified Centrifuged Blood Smear (MCBS) as a sensitive, specific and cost effective technique in malaria diagnosis. Also we aim to detect if presence of certain haematological indices would increase the probability of malaria in patients with acute febrile illness. Presence of such an indicator would prompt a more diligent search for malarial parasite and prompt institution of specific therapy.
\end{abstract}

Materials and methods: 328 patients with symptoms suspicious of malaria were taken as cases. 200 others with no clinical suspicion of malaria acted as controls. Venous blood was collected and subjected to three techniques for diagnosis of malaria; Peripheral Blood Smear examination (PBS), Modified Centrifuged Blood Smear (MCBS) and Antigen detection (dipstick method). The blood was also subjected to analysis of Haemoglobin $(H b)$ value, Total WBC count (WBC), Platelet count, Differential count (DC) and Red cell Distribution Width $(R D W)$.

Results: Modified Centrifuged Blood Smear method (MCBS) improves the sensitivity of peripheral blood smear method without compromising on specificity. Out of the haematological parameters assessed in this study, thrombocytopenia and anaemia were found to be indicators of malaria.

Conclusion: Use of MCBS in place of PBS will eliminate a lot of false negatives; also it is cost effective and requires no special training. Thrombocytopenia and anaemia have a strong association with malaria. Presence of these parameters in a clinically suspicious case should alert the clinician for the presence of malaria.

Keywords: antigen detection, malaria diagnosis, modified centrifuged blood smear, sensitive method, thrombocytopenia

\section{Introduction}

The earliest symptoms of malaria are very nonspecific and variable such as fever, headache, body ache, malaise, fatigue and abdominal discomfort. The nonspecific nature of the clinical presentation of malaria may lead to over-treatment of malaria in malaria endemic areas and missing the diagnosis of malaria in lowtransmission areas. Therefore, precise laboratory diagnosis and species identification is very essential.

The laboratory diagnosis of malaria is done by different techniques such as the conventional thin and thick peripheral blood smears (PBS), concentration techniques such as centrifuged buffy coat smears (CBCS) and fluorescent $(\mathrm{QBC})$ technique, serologic tests such as the detection of parasite-specific proteins' Rapid Diagnostic Tests (RDT) and Polymerase Chain Reaction (PCR). These techniques have their own advantages and disadvantages with respect to sensitivity, specificity, time consumption, cost effectiveness, ease of procedure etc. It would be of great help if MCBS (modified centrifuged blood smear), a technique that utilizes most of the advantages, while eliminating most of the disadvantages of the above techniques, is implemented [1]. Also a variety of haematological alterations like progressively increasing anaemia, thrombocytopenia, leucocytosis Page 2 of 12 and leukopenia and rarely Disseminated Intravascular Coagulation (DIC) have been reported in Plasmodium falciparum malaria [2]. The present study aims to detect if certain haematological indices would increase the probability of malaria in patients with acute febrile illness. Presence of such an indicator may heighten the suspicion for malaria, prompting a more diligent search for the malaria parasite, and prompt institution of specific therapy. 


\begin{abstract}
II. Aims And Objectives
2.1 To assess the feasibility of Modified Centrifuged Blood smear (MCBS) test in early detection of malaria parasite.

2.2 To compare the detection of malaria parasite in clinically suspected cases by methods such as PBS, MCBS and antigen detection (dipstick method).

2.3 To determine whether change in any of the haematological parameters in malaria can play a significant role in predicting presence of malaria parasite in clinically suspected cases.

2.4 To determine whether MCBS can be said to be a new technique that utilizes most of the advantages, while eliminating most of the disadvantages of the conventional techniques.
\end{abstract}

\title{
III. Materials And Methods
}

The present study was done in a tertiary care hospital during the period from November 2009 to November 2011. 328 patients with symptoms suspicious of malaria (fever with chills, headache and nausea and vomiting) were enrolled in the study. Blood from 200 other patients, who had no clinical suspicion of malaria, was also taken and they acted as controls. From each of the 328 patients, detailed clinical history including age, sex, presenting complaints was taken. $2 \mathrm{ml}$ of venous blood was collected in an EDTA bulb, subjected to three techniques for diagnosis of malaria; Peripheral Blood Smear examination (PBS), Modified Centrifuged Blood Smear (MCBS) and Antigen detection (dipstick method). The MCBS method is described below. The patient was declared to be having malaria if he was positive by any one of the methods employed and was called a CASE. The blood was also subjected to analysis by a three-part haematology analyser and Hb value, total WBC count, platelet count and RDW were noted. Differential count was done by peripheral smear examination. Similarly, blood from 200 patients negative for malarial symptoms was subjected to assessment of the same haematological parameters and were called CONTROLS. They were tested for malaria by all the three methods as well.

Modified Centrifuged Blood Smear (Mcbs) Technique [FIGURE 1\&2] The centrifuged buffy coat smear (CBCS) which has been used in the past involves collection of $2 \mathrm{ml}$ venous blood into anticoagulant bottles, filling the wintrobe's tube and centrifugation for 20-30 min, finally obtaining buffy coat layer onto a slide. This is a very cumbersome procedure. Although capillary tubes were used in the past, it was unacceptable due to problematic procedure and lack of standardization. [22]

The present study aims at modification of the centrifuged buffy coat smear (CBCS) by simplification of the procedure as follows:

1. Use of heparinized micro PCV tubes - this reduces the volume of the blood; it can be obtained even with finger prick.

2. High speed centrifugation - this reduces the centrifugation time.

3. Tubes to be cut with a special instrument in order to avoid shreds of glass pieces.

\section{Method}

4. The blood samples were collected in heparinized capillary (haematocrit tubes) and one end of the tube was sealed using bees wax.

5. The tubes were then centrifuged in a micro capillary centrifuge at $6000 \mathrm{rpm}$ for $5 \mathrm{~min}$.

6. The capillary was cut at the junction of buffy coat with plasma and a part of plasma, the buffy coat and a small part of RBC column were pushed onto the slide using a steel wire.

7. Smears were prepared from this material, allowed to air dry, fixed with absolute methanol for 1 min and stained with Field's stain in the same way as PBS was stained. Page 3 of 12 These smears had thickness equivalent to peripheral blood smears, providing an advantage of including the concentration of parasitized RBCs in a thin smear. The smears were examined for a maximum period of 5 min before presenting the negative report.

\section{Results}

Out of the 328 patients clinically suspicious of malaria (having fever with chills, nausea or vomiting), 146 patients were positive for malaria. These 146 patients or cases will be referred to as "Study Group" henceforth. Another 200 patients who were not clinically suspicious of malaria will be used to compare the haematological values with study group and will be referred to as "Control Group" henceforth. In our study the maximum numbers of cases were seen in the age group of $20-40 y r s$ (66\% of cases). The mean age was 32.4 years. Cases showed a male preponderance with a ratio of 4:1. P. Vivax was the predominant species in our study population comprising $77 \%$ of all cases [FIGURE 3\&4]. We found that out of 146 cases, 95 cases (65.06\%) were positive by PBS, $113(77.39 \%)$ were positive by MCBS and $145(99.31 \%)$ were positive by antigen detection. MCBS detected $12.33 \%$ of the cases that were missed on PBS. The antigen detection method though detected $22.61 \%$ cases missed on MCBS, however it missed one case of P. vivax that was positive on 
PBS and MCBS; hence its sensitivity was calculated to $99.31 \%$ (Table 1\&2). The analysis of the different methods used is given in the following table. We took antigen as gold standard to compare the other two methods (Table 3). We saw that prevalence of anaemia was higher in females than males by a ratio of 1.5:1 and higher in P. falciparum than P. vivax malaria by a ratio of $2: 1$. The association of anaemia with malaria was highly significant $(\mathrm{p}<0.05)$ (Table 4). Prevalence of thrombocytopenia was more in malaria cases than controls by a ratio of 3.4:1. Also prevalence was more in P. falciparum than P. vivax by a ratio of $1.05: 1$. Association of thrombocytopenia with malaria was highly significant $(\mathrm{p}<0.05)$ (Table 5). Both cases and controls showed normal counts in $63.69 \%$ and $71.5 \%$ cases respectively. However, we found that there was a significant association between leucocytosis and malaria $(\mathrm{p}<0.05)$ and leukopenia and malaria $(\mathrm{p}<0.05)$. There was no significant difference in Leucocyte counts among malaria species. There was no statistically significant association between malaria and monocytosis, neutropenia, lymphocytosis, lymphocytopenia, basophilia and raised RDW. ( $>0.05)$. However, there was significant association between neutrophilia and eosinophilia and malaria $(\mathrm{p}<0.05)$ in our study. Sensitivity and specificity as well as mean values of haematological parameters is mentioned in Table $6 \& 7$.

\section{Discussion}

Microscopic examination remains the "gold standard" for laboratory confirmation of malaria [3]. It is an established, relatively simple technique that is familiar to most laboratorians. It can confirm the presence of parasites in patient's blood, determine the species and also give an idea of the degree of parasitemia. The smears are able to provide all 3 of these vital pieces of information to the doctor to guide the initial treatment decisions that need to be made acutely [4]. However, microscopic parasitological diagnosis requires continued personnel training and supervision in addition to a minimum laboratory structure. Additionally, such a test is prone to large observer-related variation and lacks sensitivity when performed by non-expert laboratory microscopists [5]. In the present study out of 146 cases, $95(65.06 \%)$ cases were diagnosed on smear out of which $76(68.85 \%)$ were P. vivax and 17(54.54\%) were P. Falciparum. 1 case was diagnosed as having mixed infections (Table 8). MCBS could detect $77.39 \%$ cases in our study (Table 9). Our study showed that MCBS performed through capillary tubes was easy to perform, affordable and could detect $12.33 \%$ cases more than PBS. However, it took more time for preparation and examining as compared to PBS. Table 10 shows comparison of MCBS with other techniques. The antigen detection kit we used had Pan Specific Aldolase (P. vivax and P. falciparum) and P. falciparum specific Lactate Dehydrogenase (pLDH). In our study, none of the cases of P. falciparum was missed by $\mathrm{pLDH}$ detection but one case of mixed infection was given as positive for P. falciparum. Aldolase missed one case of P. vivax which was positive on PBS and MCBS. This might have been due to low level antigenemia in early infection. Aldolase also detected two control cases as positive for vivax malaria. They were followed up and were found to be treated cases. They might have been positive due to persistent antigenemia. PLDH and aldolase sensitivity and comparison with other methods is shown in Table 11 and 12. Page 4 of 12 Thrombocytopenia was present in $78.76 \%$ of the patients in our study. There was no significant difference in thrombocytopenia between P. vivax cases $(78.21 \%)$ and P. falciparum cases $(81.81 \%)$. There was a strong association between thrombocytopenia and malaria $(\mathrm{p}<0.05)$. No definitive mechanism has been described for thrombocytopenia but decreased megakaryopoeisis can be excluded because platelet forming megakaryocytes are usually normal or increased in the bone marrow [5]. Immune mediated destruction of circulating platelets has been postulated, and it has been found that malaria patients have elevated levels of platelet bound IgG [5][6][7]. Another proposed mechanism is that of platelets engulfing malarial parasites and in the process becoming damaged and thus being removed from circulation [5]. Anaemia was seen in 57.33\% cases (P. vivax $46.42 \%$, P. falciparum $75.75 \%$ ). The association of anaemia with malaria was statistically significant $(\mathrm{p}<0.05)$. The pathogenesis of anaemia in malaria is multifactorial. A complex chain of pathogenic processes involving mechanical destruction of parasitized RBCs, marrow suppression, ineffective erythropoiesis and accelerated immune destruction of non-parasitized RBCs has been implicated [8].

Our study showed leucocytosis, leukopenia, neutrophilia and eosinophilia to be significantly associated with malaria. The findings of our study were concordant with other studies (Table 13-21).

\section{Conclusion}

Microscopic examination remains the "gold standard" for laboratory confirmation of malaria [3]. It is an established, relatively simple technique that is familiar to most laboratorians. It can confirm the presence of parasites in patient's blood, determine the species and also give an idea of the degree of parasitemia. The smears are able to provide all 3 of these vital pieces of information to the doctor to guide the initial treatment decisions that need to be made acutely [4]. However, microscopic parasitological diagnosis requires continued personnel training and supervision in addition to a minimum laboratory structure. Additionally, such a test is prone to large observer-related variation and lacks sensitivity when performed by non-expert laboratory microscopists [5]. In 
the present study out of 146 cases, $95(65.06 \%)$ cases were diagnosed on smear out of which $76(68.85 \%)$ were P. vivax and 17(54.54\%) were P. Falciparum. 1 case was diagnosed as having mixed infections (Table 8). MCBS could detect $77.39 \%$ cases in our study (Table 9). Our study showed that MCBS performed through capillary tubes was easy to perform, affordable and could detect $12.33 \%$ cases more than PBS. However, it took more time for preparation and examining as compared to PBS. Table 10 shows comparison of MCBS with other techniques. The antigen detection kit we used had Pan Specific Aldolase (P. vivax and P. falciparum) and P. falciparum specific Lactate Dehydrogenase (pLDH). In our study, none of the cases of P. falciparum was missed by $\mathrm{pLDH}$ detection but one case of mixed infection was given as positive for $\mathrm{P}$. falciparum. Aldolase missed one case of P. vivax which was positive on PBS and MCBS. This might have been due to low level antigenemia in early infection. Aldolase also detected two control cases as positive for vivax malaria. They were followed up and were found to be treated cases. They might have been positive due to persistent antigenemia. PLDH and aldolase sensitivity and comparison with other methods is shown in Table 11 and 12.

Thrombocytopenia was present in $78.76 \%$ of the patients in our study. There was no significant difference in thrombocytopenia between P. vivax cases $(78.21 \%)$ and P. falciparum cases $(81.81 \%)$. There was a strong association between thrombocytopenia and malaria $(\mathrm{p}<0.05)$. No definitive mechanism has been described for thrombocytopenia but decreased megakaryopoeisis can be excluded because platelet forming megakaryocytes are usually normal or increased in the bone marrow [5]. Immune mediated destruction of circulating platelets has been postulated, and it has been found that malaria patients have elevated levels of platelet bound IgG [5][6][7]. Another proposed mechanism is that of platelets engulfing malarial parasites and in the process becoming damaged and thus being removed from circulation [5]. Anaemia was seen in 57.33\% cases (P. vivax 46.42\%, P. falciparum 75.75\%). The association of anaemia with malaria was statistically significant $(\mathrm{p}<0.05)$. The pathogenesis of anaemia in malaria is multifactorial. A complex chain of pathogenic processes involving mechanical destruction of parasitized RBCs, marrow suppression, ineffective erythropoiesis and accelerated immune destruction of non-parasitized RBCs has been implicated [8].

Our study showed leucocytosis, leukopenia, neutrophilia and eosinophilia to be significantly associated with malaria. The findings of our study were concordant with other studies (Table 13-21).

\section{Conclusion}

The Modified Centrifuged Blood Smear method (MCBS) utilizes some special equipment but these are cheap and can be easily mobilized in far flung areas. The technique improves the sensitivity of peripheral blood smear method without compromising on specificity. The principle of centrifugation, which is employed in Quantitative Buffy coat technique, is employed here and direct visualization of parasites is also possible, thus eliminating disadvantages of quantitative buffy coat technique. Out of the haematological parameters assessed in this study, thrombocytopenia and anaemia were found to be statistically associated with malaria. These two parameters present in a clinically suspected case of malaria can point towards the diagnosis of malaria.

Table 1

Results according to methods used for detection in study group

\begin{tabular}{|c|c|c|c|c|c|c|}
\hline & PV & PF & MIXED & $\begin{array}{c}\text { TOTAL } \\
\text { POSITIVE }\end{array}$ & NEGATIVE & TOTAL \\
\hline PBS & 76 & 18 & 1 & 95 & 233 & 328 \\
\hline MCBS & 90 & 22 & 1 & 113 & 215 & 328 \\
\hline ANTIGEN & 111 & 34 & 0 & 145 & 183 & 328 \\
\hline
\end{tabular}

Table 2

\begin{tabular}{|c|c|c|c|c|c|c|}
\multicolumn{8}{l|}{ Results according to methods used for detection in control group } \\
\hline & PV & PF & MIXED & $\begin{array}{c}\text { TOTAL } \\
\text { POSITIVE }\end{array}$ & NEGATIVE & TOTAL \\
\hline PBS & O & O & O & O & 200 & 200 \\
\hline MCBS & O & O & O & 0 & 200 & 200 \\
\hline ANTIGEN & 2 & 0 & 0 & 2 & 198 & 200 \\
\hline
\end{tabular}

Table 3

Analysis of methods used for detection of malaria

\begin{tabular}{|c|c|c|c|c|c|}
\hline Method & Sensitivity & Specificity & PPV & NPV & $\begin{array}{c}\text { kappa } \\
\text { coefficient of } \\
\text { agreement }\end{array}$ \\
\hline PBS & 63.33 & 99.45 & 98.95 & 78.44 & 0.67 \\
\hline MCBS & 77.93 & 99.45 & 99.12 & 85.04 & 0.77 \\
\hline
\end{tabular}


Table 4

Anaemia distribution

(Normal range [21] - males 13-17gm\%, females - 12-15 gm \%)

\begin{tabular}{|c|c|c|c|c|c|}
\hline & $\begin{array}{c}\text { MALES } \\
\mathrm{Hb}<13 \\
\mathrm{gm} \%\end{array}$ & $\begin{array}{c}\text { MALES with } \\
\text { normal Hb } \\
(>13 \mathrm{gm} \%)\end{array}$ & $\begin{array}{c}\text { FEMALES } \\
\mathrm{Hb}<12 \mathrm{gm} \%\end{array}$ & $\begin{array}{c}\text { Females with } \\
\text { normal Hb (12 } \\
\mathrm{gm} \%)\end{array}$ & \multirow{2}{*}{146} \\
\hline $\mathrm{PV}$ & 35 & 54 & 17 & 6 & \multirow{2}{*}{2} \\
\hline PF & 19 & 8 & 6 & 0 & \multirow{2}{*}{200} \\
\hline MIXED & 1 & 0 & 0 & 42 & \\
\hline CONTROLS & 36 & 95 & 27 & & \\
\hline
\end{tabular}

Distribution of cases according to platelet count

\begin{tabular}{|c|c|c|c|c|c|}
\hline & $\begin{array}{c}\text { COUNT } \\
1-1.5 \mathrm{LAKH} / \mu \mathrm{l}\end{array}$ & $\begin{array}{c}\text { COUNT } 50,000 \\
-1 \mathrm{LAKH} / \mu \mathrm{l}\end{array}$ & $\begin{array}{c}\text { COUNT } \\
<50,000 / \mu l\end{array}$ & $\begin{array}{c}\text { COUNT } \\
>1.5 \mathrm{LAKH} / \mu \mathrm{l}\end{array}$ & TOTAL \\
\hline PV & 15 & 43 & 29 & 25 & \multirow{3}{*}{146} \\
\hline $\mathrm{PF}$ & 4 & 15 & 8 & 6 & \\
\hline MIXED & 0 & 0 & 1 & 0 & \\
\hline CONTROLS & 1 & 19 & 26 & 154 & 200 \\
\hline
\end{tabular}

Table 6

Haematological parameters, their sensitivity, specificities and p values

\begin{tabular}{|c|c|c|c|c|c|c|}
\hline & Sensitivity & Specificity & PPV & NPV & Chi Square & P value \\
\hline $\begin{array}{c}\text { Anemia (Hb<13 males, } \\
\quad<12 \text { females) }\end{array}$ & 57.53 & 68.5 & 57.14 & 68.84 & 23.4 & $\begin{array}{c}0 \\
(<0.05)\end{array}$ \\
\hline $\begin{array}{c}\text { Thrombocytopenia } \\
\left(<1,50,000 / \mathrm{mm}^{3}\right)\end{array}$ & 78.76 & 77 & 71.42 & 84.61 & 105.4 & $\begin{array}{c}0 \\
(<0.05) \\
\end{array}$ \\
\hline $\begin{array}{l}\text { Leukocytosis } \\
\left(>10,000 / \mathrm{mm}^{3}\right)\end{array}$ & 6.84 & 81.5 & 21.27 & 54.51 & 9.758 & $\begin{array}{r}0.001 \\
(<0.05)\end{array}$ \\
\hline $\begin{array}{l}\text { Leucopenia } \\
\left(<4000 / \mathrm{mm}^{3}\right)\end{array}$ & 41.74 & 90 & 68.25 & 63.61 & 21.14 & $\begin{array}{c}0 \\
(<0.05) \\
\end{array}$ \\
\hline Neutrophilia (>80\%) & 13.69 & 96.5 & 74.7 & 60.5 & 12.2 & $\begin{array}{l}0.0004 \\
(<0.05) \\
\end{array}$ \\
\hline Neutropenia (<40\%) & 6.16 & 93 & 39.13 & 57.58 & 0.09 & $\begin{array}{c}0.75 \\
(>0.05) \\
\end{array}$ \\
\hline Monocytosis (>10\%) & 08.21 & 95.5 & 57.14 & 58.76 & 2.04 & $\begin{array}{c}0.15 \\
(>0.05) \\
\end{array}$ \\
\hline Eosinophilia (>6\%) & 01.30 & 72 & 3.44 & 50 & 41.005 & $\begin{array}{c}0 \\
(<0.05)\end{array}$ \\
\hline Lymphocytosis (>40\%) & 21.91 & 81 & 45.71 & 58.69 & 0.445 & $\begin{array}{r}0.504 \\
(>0.05) \\
\end{array}$ \\
\hline $\begin{array}{c}\text { Lymphocytopenia } \\
(<20 \%)\end{array}$ & 28.76 & 73.5 & 44.21 & 58.56 & 0.217 & $\begin{array}{c}0.64 \\
(>0.05) \\
\end{array}$ \\
\hline RDW (>14\%) & 41.09 & 59.5 & 45.71 & 58.69 & 0.012 & $\begin{array}{c}0.911 \\
(>0.05)\end{array}$ \\
\hline
\end{tabular}

Table 7

Haematological parameters Mean values $(\lfloor 25 \mathrm{D})$

\begin{tabular}{|c|c|c|c|c|c|c|c|c|c|c|}
\hline & $\begin{array}{l}\text { Age in } \\
\text { years }\end{array}$ & $\begin{array}{c}\mathrm{Hb} \\
\text { value } \\
\text { (gm\%) } \\
\text { Meant } \\
\text { 2SD }\end{array}$ & $\begin{array}{c}\text { TLC } \\
(/ \mathrm{mm} 3 \mid \\
\text { Mean } \\
\text { 2SD }\end{array}$ & $\begin{array}{c}\text { Neutrophil } \\
s(\%) \\
\text { Meant } \\
2 S D\end{array}$ & $\begin{array}{c}\text { Lymphocytes } \\
(80) \\
\text { Mean } \pm \\
2 S D\end{array}$ & $\begin{array}{c}\text { Eosinophils } \\
(\%) \\
\text { Meant } \\
2 S D\end{array}$ & $\begin{array}{c}\text { Monocyte } \\
\text { s(\%) } \\
\text { Meant } \\
\text { 2SD }\end{array}$ & $\begin{array}{c}\text { Basophils } \\
(\%) \\
\text { Meant } \\
250\end{array}$ & $\begin{array}{l}\text { Platelets } \\
(/ \mu l) \\
\text { Meant } \\
2 S D\end{array}$ & $\begin{array}{l}\text { RDW } \\
(70) \\
\text { Meant } \\
\text { 2SD }\end{array}$ \\
\hline $\begin{array}{l}\text { STUDY } \\
\text { GROUP }\end{array}$ & $\begin{array}{c}32.4 \\
( \pm 12.63)\end{array}$ & $\begin{array}{c}12.32 \\
( \pm 2.50)\end{array}$ & $\begin{array}{c}5732 \\
( \pm 2509)\end{array}$ & $\begin{array}{c}64.09 \\
( \pm 14.85)\end{array}$ & $\begin{array}{c}28.91 \\
( \pm 13.14)\end{array}$ & $\begin{array}{c}2.34 \\
( \pm 1.25)\end{array}$ & $\begin{array}{c}4.76 \\
( \pm 3.19)\end{array}$ & $\begin{array}{c}0.08 \\
( \pm 0.27)\end{array}$ & $\begin{array}{c}114589 \\
( \pm 79276)\end{array}$ & $\begin{array}{l}14.16 \\
( \pm 2.49)\end{array}$ \\
\hline $\begin{array}{l}\text { CONTROL } \\
\text { GROUP }\end{array}$ & $\begin{array}{c}31.57 \\
( \pm 13.09)\end{array}$ & $\begin{array}{c}13.1 \\
( \pm 2.68)\end{array}$ & $\begin{array}{c}7919 \\
( \pm 3800)\end{array}$ & $\begin{array}{c}59.25 \\
( \pm 13.66)\end{array}$ & $\begin{array}{c}32.48 \\
( \pm 13.1)\end{array}$ & $\begin{array}{c}4.47 \\
( \pm 2.61)\end{array}$ & $\begin{array}{c}3.67 \\
( \pm 2.46)\end{array}$ & $\begin{array}{c}0.37 \\
( \pm 0.51)\end{array}$ & $\begin{array}{c}217190 \\
( \pm 88431)\end{array}$ & $\begin{array}{r}13.93 \\
( \pm 1.87)\end{array}$ \\
\hline
\end{tabular}


Table 8

Percentage of cases positive by PBS

\begin{tabular}{|c|c|}
\hline Study series & Percentage of positive cases \\
\hline Singh et al (2010) [9] & $51.10 \%$ \\
\hline Batwala et al (2010) [10] & $47.2 \%$ \\
\hline Bhandari et al (2008) [1] & $86.79 \%$ \\
\hline Binesh Lal Y et al (1999)[11] & $97.82 \%$ \\
\hline Present study & $65.06 \%$ \\
\hline
\end{tabular}

Table 9

Percentage of cases positive by MCBS

\begin{tabular}{|c|c|}
\hline MCBS Method & \% Positivity \\
\hline Bhandariet al (2008) [1] & $86.79 \%$ \\
\hline Duangdee et al (2011) [12] & - \\
\hline Present study & $77.39 \%$ \\
\hline Akhtar et al (2010)79 (CBCS)\# & $93.33 \%$ \\
\hline
\end{tabular}

Table 10

Comparison of $M C B S$ with PBS

\begin{tabular}{|c|c|}
\hline STUDY & $\begin{array}{c}\text { \%cases which were detected by MCBS over and above } \\
\text { those detected by PBS (advantage gained through } \\
\text { MCBS) }\end{array}$ \\
\hline Bhandari et al (2008) [1] & $13.21 \%$ \\
\hline Duangdee et al (2011) [12] & $27.8 \%$ \\
\hline Present study & $12.33 \%$ \\
\hline Akhtar et al (2010][13] (CBCS) & $9.31 \%$ \\
\hline
\end{tabular}

Table 11

Plasmodium lactate dehydrogenase sensitivity and specificity /Pf specific

\begin{tabular}{|c|c|c|}
\hline PLDH & Sensitivity & Specificity \\
\hline Palmer et al (2003) [14] & $96.8 \%$ & $99.4 \%$ \\
\hline Ratasimbasoa A. et al (2007) [15] & $92.6 \%$ & $98.1 \%$ \\
\hline Van den Broek et al (2006) [16] & $83.6 \%$ & $97.8 \%$ \\
\hline Moody A (2002) [17] & $96 \%$ & $100 \%$ \\
\hline De Monbrison et al (2004) [18] & $84.3 \%$ & $98.4 \%$ \\
\hline Present study & $100 \%$ & $100 \%$ \\
\hline
\end{tabular}

Table 12

Aldolase sensitivity and specificity (Pan Pv and Pf)

\begin{tabular}{|c|c|c|}
\hline Study series & Sensitivity & Specificity \\
\hline Farcas G.A. et al (1994) [19] & $86.7 \%$ & $98.7 \%$ \\
\hline De Monbrison et al (2004) [18] & 100 & $98.9 \%$ \\
\hline Miller R.S. (2006) [20] & $82.5 \%$ & $89.8 \%$ \\
\hline Van den Broek et al (2006) [16] & $\mathbf{8 1 . 4 \%}$ & $89.9 \%$ \\
\hline Present Study & $99.1 \%$ & $99.51 \%$ \\
\hline
\end{tabular}

Table 13

Thrombocytopenia and malaria

\begin{tabular}{|c|c|}
\hline Study series & $\begin{array}{c}\text { Percentage of malaria cases showing } \\
\text { thrombocytopenia. }\end{array}$ \\
\hline Abro AH et al (2008) [23] & $81 \%$ (PV), 87\% (PF) \\
\hline Khan et al (2010) [24] & $74 \%$ \\
\hline Memon A. et al (2006) [25] & $70 \%$ \\
\hline Bhandary N. et al (1994) [26] & $73.89 \%(\mathrm{PV}), 83.3 \%$ (PF) \\
\hline Agravat et al (2010) [27] & $81.5 \%$ \\
\hline Maina Ret al. (2010) [28] & $49 \%$ \\
\hline Lathia TB et al (2004) [2] & $60 \%$ \\
\hline Present Study & $78.21 \%(\mathrm{PV}), 81.81 \%$ (PF) \\
\hline
\end{tabular}

Table 14

Anemia and malaria

\begin{tabular}{|c|c|}
\hline Study series & Percentage of cases showing anemia \\
\hline Abro AH et al (2008) [23] & $63 \%(\mathrm{PV}), 67 \%(\mathrm{PF})$ \\
\hline Khan et al (2010) [24] & $61 \%$ \\
\hline Bashawari et al (2002) [29] & $59.2 \%$ \\
\hline Jain M et al (2005) [30] & $94.28 \%$ \\
\hline Present Study & $46.42 \%(\mathrm{PV}), 75.75 \%(\mathrm{PF})$ \\
\hline
\end{tabular}


Table 15

Variation in Total Leucocyte count in malaria

\begin{tabular}{|c|c|c|c|}
\hline Study series & Normal TLC & Leucocytosis & Leucopenia \\
\hline Abro AH et al (2008) [23] & $84 \%$ (PV), & $2 \%(\mathrm{PV})$, & $14 \%(\mathrm{PV})$, \\
& $86 \%(\mathrm{PF})$ & $4 \%(\mathrm{PF})$ & $10 \%(\mathrm{PF})$ \\
\hline Taylor et al (2008) [31] & $85 \%$ & $5.9 \%$ & $9.2 \%$ \\
\hline Erhart et al (2004) [32] & $68.1 \%(\mathrm{PV})$, & $5.7 \%(\mathrm{PV})$, & $20.8 \%(\mathrm{PV})$, \\
& $68.59 \%(\mathrm{PF})$ & $4.3 \%(\mathrm{PF})$ & $27 \%(\mathrm{PF})$ \\
\hline Bashawari et al (2002)[29] & $78.3 \%$ & $7.2 \%$ & $13.3 \%$ \\
\hline Jadhav et al (2003) [33] & $81.1 \%$ & $1.7 \%(\mathrm{PV})$, & $15.2 \%(\mathrm{PV})$, \\
& & $6.8 \%(\mathrm{PF})$ & $10.7 \%(\mathrm{PF})$ \\
\hline \multirow{2}{*}{ Present Study } & $66.07 \%(\mathrm{PV})$, & $5.35 \%(\mathrm{PV})$, & $28.57 \%(\mathrm{PV}), 33.33 \%$ \\
& $54.54 \%(\mathrm{PF})$ & $12.12 \%(\mathrm{PF})$ & $(\mathrm{PF})$ \\
\hline
\end{tabular}

Table 16

Variation in Neutrophil count in malaria

\begin{tabular}{|c|c|c|c|}
\hline Study series & Normal & Neutrophilia & Neutropenia \\
\hline Abro AH et al (2008) [23] & $93 \%(\mathrm{PV}), 93 \%(\mathrm{PF})$ & $\begin{array}{c}3 \%(\mathrm{PV}), \\
3 \%(\mathrm{PF})\end{array}$ & $\begin{array}{c}3 \%(\mathrm{PV}), \\
4 \%(\mathrm{PF})\end{array}$ \\
\hline Bashawari et al (2002) [29] & $67.9 \%$ & $8.3 \%$ & $11.6 \%$ \\
\hline Jadhav et al (2003) [33] & $79.3 \%$ & $5.6 \%$ & $15.1 \%$ \\
\hline \multirow{2}{*}{ Present Study } & $82.14 \%(\mathrm{PV})$, & $11.6 \%(\mathrm{PV})$, & $6.25 \%(\mathrm{PV})$, \\
& $72.72 \%(\mathrm{PF})$ & $21.21 \%(\mathrm{PF})$ & $6.06 \%(\mathrm{PF})$ \\
\hline
\end{tabular}

Table 17

Variation in Monocyte count in malaria

\begin{tabular}{|c|c|c|c|}
\hline Study series & $\begin{array}{c}\text { Normal monocyte } \\
\text { count }\end{array}$ & Monocytosis & Monocytopenia \\
\hline Abro AH et al (2008) [23] & $90 \%(\mathrm{PV}), 90 \%$ (PF) & $10 \%(\mathrm{PV})$, & $3 \%(\mathrm{PV})$, \\
& $72.7 \%$ & $10 \%(\mathrm{PF})$ & $1 \%(\mathrm{PF})$ \\
\hline Bashawari et al (2002)98 & $92 \%(\mathrm{PV})$, & $8 \%(\mathrm{PV})$, & $6.1 \%$ \\
\hline Present Study & $90.91 \%(\mathrm{PF})$ & $9.09 \%(\mathrm{PF})$ & $0 \%(\mathrm{PV}), 0 \%(\mathrm{PF})$ \\
\hline
\end{tabular}

Table 18

Variation in lymphocyte count in malaria

\begin{tabular}{|c|c|c|c|}
\hline Study series & Normal & Lymphocytosis & Lymphopenia \\
\hline Abro AH et al (2008) [23] & $64 \%(\mathrm{PV})$, & $0 \%(\mathrm{PV})$, & $36 \%(\mathrm{PV}), 15 \%(\mathrm{PF})$ \\
& $85 \%(\mathrm{PF})$ & $0 \%(\mathrm{PF})$ & \\
\hline Bashawari et al (2002) [29] & $31.2 \%$ & $13.6 \%$ & $42.9 \%$ \\
\hline Present Study & $45.53 \%(\mathrm{PV}), 45.45 \%$ & $24.11 \%(\mathrm{PV}), 33.33 \%$ & $30.35 \%(\mathrm{PV})$, \\
& $(\mathrm{PF})$ & $(\mathrm{PF})$ & $27.27 \%(\mathrm{PF})$ \\
\hline
\end{tabular}

Table 19

\begin{tabular}{|c|c|c|c|}
\hline \multicolumn{5}{|c|}{ Variation in Eosinophil count in malaria } \\
\hline Study series & $\begin{array}{c}\text { Normal } \\
\text { Eosinophil count }\end{array}$ & Eosinophilia & Eosinopenia \\
\hline Abro AH et al (2008) [23] & $97 \%(\mathrm{PV})$, & $0 \%(\mathrm{PV})$, & $0 \%(\mathrm{PV}), 0 \%(\mathrm{PF})$ \\
& $100 \%(\mathrm{PF})$ & $3 \%(\mathrm{PF})$ & \\
\hline Bashawari et al (2002) [29] & $41 \%$ & $1.8 \%$ & $57.2 \%$ \\
\hline Present Study & $99.11 \%(\mathrm{PV}), 96.97 \%(\mathrm{PF})$ & $0.8 \%(\mathrm{PV}), 3 \%(\mathrm{PF})$ & $0 \%(\mathrm{PV}), 0 \%(\mathrm{PF})$ \\
\hline
\end{tabular}

Table 20

Variation in basophil count in malaria

\begin{tabular}{|c|c|c|}
\hline Study series & Normal Basophil count & Basophilia \\
\hline Abro AH et al (2008) [23] & $100 \%$ & $0 \%$ \\
\hline Bashawari et al (2002) [29] & $98.8 \%$ & $1.2 \%$ \\
\hline Present Study & $100 \%$ & $0 \%$ \\
\hline
\end{tabular}

Table 21

Variation in RDW in malaria

\begin{tabular}{|c|c|c|}
\hline Study series & RDW raised & Normal RDW \\
\hline Lathia TB et al (2004) [2] & $41 \%$ & $59 \%$ \\
\hline Agravat et al (2010) [27] & $95.7 \%$ & $4.3 \%$ \\
\hline Present Study & $41.09 \%$ & $58.91 \%$ \\
\hline
\end{tabular}




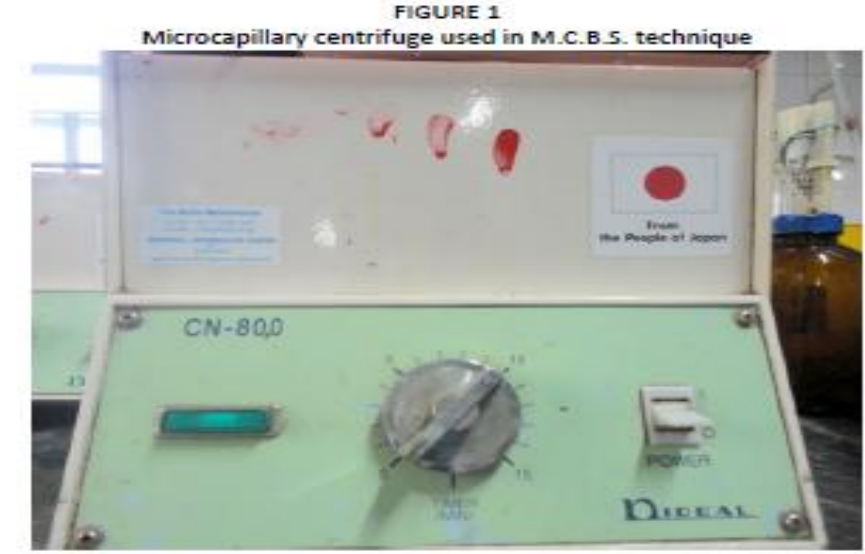

FIGURE 2

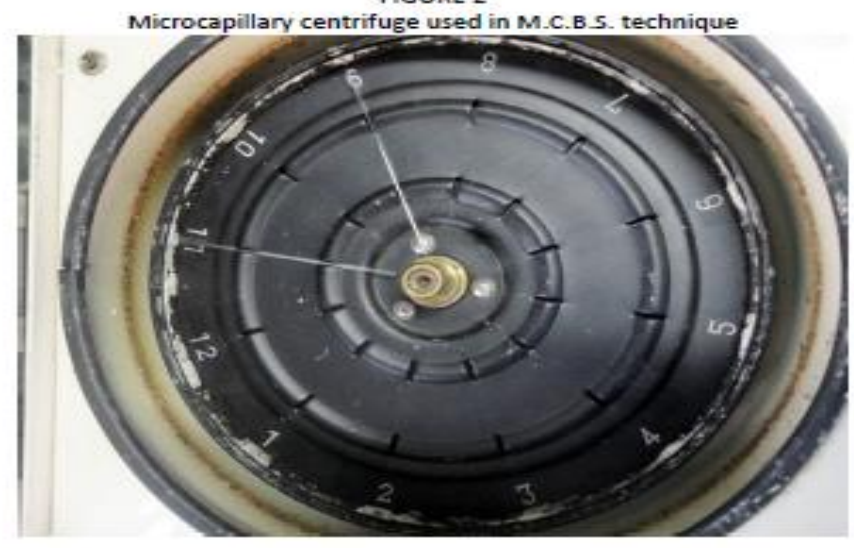

FIGURE 3

P. Vivax Ring forms on M.C.B.S. (arrow head) [100x) (Field's stain)

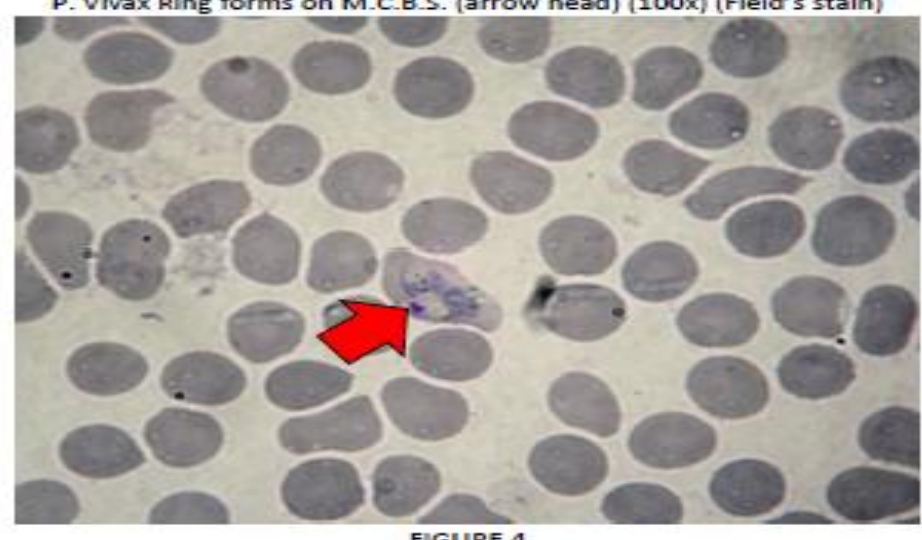

FIGURE 4

P. Falciparum ring forms on M.C.B.S. (arrow head) (100x) (Field's stain)

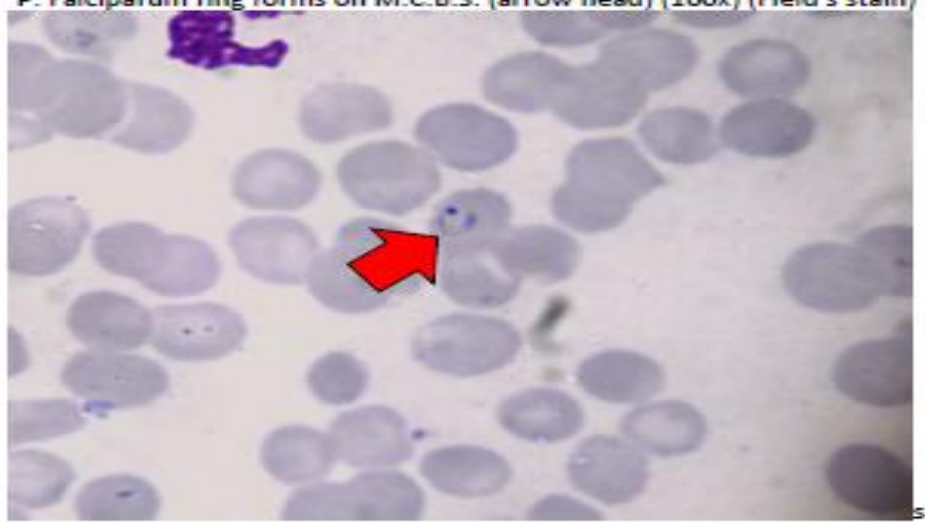




\section{Bibliography}

[1]. Bhandari PL, Raghuveer CV, Rajeev A, Bhandari PD. Comparative study of peripheral blood smear, quantitative buffy coat and modified centrifuged blood smear in malaria diagnosis. Indian J Pathol Microbiol 2008 Jan-Mar; 51(1): 108-12.

[2]. Lathia TB, Joshi R. Can hematological parameters discriminate malaria from non malarious acute febrile illness in the tropics. Indian J Med Sci 2004; 58: 239-244.

[3]. World Health organization, Guidelines for treatment of malaria. Geneva 2010; p. xi.

[4]. Malaria diagnosis (U.S.)-Microscopy, Global Health-division of Parasitic diseases, Centre for disease control and prevention (online) (cited 2011 Oct 26) Available from URL: http://www.cdc.gov/malaria/diagnosis_treatment/microscopy.html

[5]. Facer CA. Hematological aspects of malaria. In: Infection and hematology. Oxford: Butterworth Heinmann Ltd, 1994: 259-94.

[6]. Perrin LH, Mackey LJ, Miescher PA. The hematology of malaria in man. Sem Hematol 1982; 19:70-81.

[7]. Essien EM. Medical Hypothesis: the circulating platelet in acute malaria infection. Brit J Hematol 1989; 72:589-90.

[8]. Sen R, Tewari AD, Sehgal PK, Singh U, Sikka R, Sen J. Clinico-hematological profile in acute and chronic falciparum malaria in children. J Coin Dis 1994; 26:31-8.

[9]. Singh N, Shukla M, Shukla M, Mehra R, Sharma S, Bharati P Et al. Field and laboratory comparative evaluation of rapid malaria diagnostic tests versus traditional and molecular techniques in India. Malaria Journal 2010; 9:191.

[10]. Batwala et al. Are rapid diagnostic tests more accurate in diagnosis of plasmodium falciparum malaria compared to microscopy at rural health centers. Malaria Journal 2010; 9:349.

[11]. Binesh Lal Y, Jayakumar S, Kalyani M, Mathew R, Shameem Banu AS, Dhinesh R. Correlation of Quantitative Buffy Coat, Blood smear and Antigen Detection in Diagnosing Malarial Infection. Journal of Clinical and Diagnostic Research. 2011 October; 5(5): 961-3.

[12]. Duangdee C, Tangpukdee N, Krudsood S, Wilairatana P, Buffy coat thick films could detect malaria parasites in patients with negative conventional thick films, Asian Pacific journal of tropical biomedicine 2011; 1-8.

[13]. Akhtar S, Maimoon S, Wilkinson A, Gowardhan V, Mahore S, Feasible choices in diagnostic methods of malaria, J Vector Borne Dis 2010 Sep; 151-54.

[14]. Palmer CJ, Bonilla JA, Bruckner DA, Barnett ED, Miller NS, Haseeb MA. Multicenter study to evaluate the OptiMAL test for rapid diagnosis of malaria in U.S. hospitals. J Clin Microbiol 2003; 41:5178-82.

[15]. Ratsimbasoa, A., A. Randriamanantena, R. Raherinjafy, N. Rasoarilalao, and D. Menard. Which malaria rapid test for Madagascar, Field and laboratory evaluation of three tests and expert microscopy of samples from suspected malaria patients in Madagascar. Am. J. Trop. Med. Hyg. 2007; 76:481-485.

[16]. Van den Broek I, Hill O, Gordillo F, Angarita B, Hamade P, Counihan H Et al. Evaluation of three rapid tests for diagnosis of P. falciparum and P. vivax malaria in Colombia. Am J Trop Med Hyg 2006; 75:1209-15.

[17]. Moody A, Rapid diagnostic tests for malaria parasites, Clin Microbiol Rev 2002; 15(1):66.

[18]. De Monbrison F, Gerome P, Chaulet JF, Wallon M, Picot S, Peyron F. Comparative diagnostic performance of two commercial rapid tests for malaria in a non-endemic area. Eur J Clin Microbiol Infect Dis 2004; 23:784-86.

[19]. Farcas GA, Zhong KJ, Lovegrove FE, Graham CM, Kain KC. Evaluation of the Binax NOW ICT test versus polymerase chain reaction and microscopy for the detection of malaria in returned travelers. Am J Trop Med Hyg 2003; 69:589-92.

[20]. Miller RS, Comparison of performance characteristics of the Binax NOW Malaria test using venous and fingerstick samples, Abstract of 55th Annual Meeting of the American Society of Tropical Medicine and Hygiene; 2006: abstr 533.

[21]. Lewis S, Bain B, Bates I. Hematological values for normal adults expressed as mean +/- 2 SD, In Dacie and Lewis practical hematology 10th ed, Churchill Livingstone: p 14.

[22]. Woo PT, Hauck L. The hematocrit centrifuge smear technique for detection of mammalian plasmodium. Trans of royal soc trop med hyg 1987; 81: 727-8

[23]. Page 12 of 12

[24]. Abro A, Ustadi A, Younis N, Abdou A, Hamed D, Saleh A, Malaria and hematological changes, Pak J med sci 2008 Apr; 24(2): 287-91.

[25]. Khan A., Hayat A, Ali A, Khan U. Frequencies of anemia and thrombocytopenia in patients of malaria: a hospital based study, Pakistan Armed Forces Medical journal 2010 Dec; 4.

[26]. Memon A., Afsar S. Thrombocytopenia in hospitalized malaria patients, Pak J Med Sci 2006 Apr-Jun; 22(2):141-43.

[27]. Bhandary N, Vikram GS, Shetty H. Thrombocytopenia in malaria, a clinical study. Biomed Res 2011; $22(4): 489-491$.

[28]. Agravat AH, Dhruva GA. Hematological changes in patients of malaria. Journal of cell and tissue research 2010; 10(3): 2325-29.

[29]. Maina R, Walsh D, Gaddy C, Hongo G, Waitumbi J, Otieno L. Impact of plasmodium falciparum infection on hematological parameters in children living in western Kenya, Malaria Journal 2010; 9(3): S4.

[30]. Bashawari LAM, Mandil AA, Bahnassy AA, Ahmed MA. Malaria: hematological aspects. Annals of Saudi Medicine 2002; 22( 56): $372-77$

[31]. Jain M, Kaur M. Comparative study of microscopic detection methods and haematological changes in malaria. Indian Journal of Pathology and Microbiology 2005 Oct; 48(4):464-7.

[32]. Taylor WR, Widjaja H, Hasan B, Ohrt C, Taufik T, Tjitra E et al. Changes in the total leukocyte and platelet counts in Papuan and non Papuan adults from northeast Papua infected with acute Plasmodium vivax or uncomplicated Plasmodium falciparum malaria. Malaria Journal 2008; 7:259.

[33]. Erhart L, Yingyeun K, Chuanak N, Buathong N, Laoboonchai A, Miller S et al. Hematologic and clinical indices of malaria in a semi immune population of western Thailand, Am J Trop Med Hyg 2004; 70(1):8-14

[34]. Jadhav UM, Singhvi R, Shah R. Prognostic Implications of White Cell Differential Count and White Cell Morphology in Malaria. J Postgrad Med 2003; 49:218-21. 